\title{
RESPONSABILIDADE CIVIL DOS INFLUENCIADORES DIGITAIS
}

\author{
Ana Paula Gilio Gasparatto* \\ Cinthia Obladen de Almendra Freitas** \\ Antônio Carlos Efing ****
}

SUMÁRIO: Introdução; 2. A Publicidade e sua regulamentação no Brasil; 3. Os influenciadores digitais e a responsabilidade civil sob a ótica da sociedade da exposição; 3.1. A sociedade da exposição; 3.2. Quem são os influenciadores digitais?; 3.3 A responsabilidade civil; 4 . Considerações finais; Referências.

RESUMO: A publicidade no Brasil é regulada tanto no âmbito estatal quanto no âmbito privado, com a finalidade de inibir a publicidade ilícita, que pode se apresentar de forma abusiva e/ou enganosa, garantindo, assim, os direitos dos consumidores. Com o avanço da tecnologia e das facilidades que a internet pode oferecer, vive-se, atualmente, em uma sociedade de exposição, onde cada vez mais os indivíduos compartilham seus interesses e opiniões. Surge então a figura do influenciador digital, indivíduo formador de opinião digital, capaz de modificar comportamentos de seus seguidores. O artigo avalia a responsabilidade civil dos influenciadores digitais em razão de indicação de produtos e serviços, justificandose o estudo frente a vulnerabilidades dos consumidores. O método lógico-dedutivo foi a base metodológica do estudo, partindo do entendimento da publicidade e sua regulamentação no Brasil para alcançar os influenciadores digitais e discutir a sua responsabilidade civil. Conclui-se pela responsabilidade objetiva dos influenciadores, visto que eles estão em vantagem quando comparados aos consumidores e atuam efetivamente por meio da indicação de produtos e serviços, de modo a impactar a vida dos seus seguidores, moldar comportamentos e motivar escolhas de consumo.

PALAVRAS-CHAVE: Influenciadores digitais; Novas tecnologias; Responsabilidade civil; Código de Defesa do Consumidor.

\footnotetext{
"Mestre em Direito Econômico e Socioambiental pela Pontifícia Universidade Católica do Paraná (PUCPR). Advogada, Brasil.

** Doutora em Informática pela PUCPR. Docente Titular da PUCPR da Escola de Direito. Docente Permanente do Programa de Pós-Graduação em Direito (PPGD) da PUCPR, Brasil. email: cinthia@ppgia.pucpr.br

${ }^{* * *}$ Doutor em Direito pela Pontifícia Universidade Católica de São Paulo (PUCSP). Docente Titular da PUCPR na Escola de Direito. Docente Permanente do Programa de Pós-Graduação em Direito (PPGD) da mesma instituição. Advogado, Brasil.
} 


\section{CIVIL RESPONSIBILITY OF DIGITAL INFLUENCE MAKERS}

ABSTRACT: Publicity in Brazil is governed by state and private laws to inhibit illicit propaganda that may be abusive and/or tricky. Consequently, consumers' rights are guaranteed. Due to technology and the means that the Internet provides, we live in an exposed society in which people share interests and opinions. The influence maker is thus born, or rather, persons who inform digital opinion may modify the behavior of their followers. Current paper, based on the logical and deductive method, evaluates the civil responsibility of digital influence makers with regard to the indications of products and services within the context of consumers' vulnerability. Publicity and its regulations in Brazil are discussed within the context of accountability of influence makers. Results show that influence makers have an objective accountability due to their advantage when compared to consumers. They affect the sale of goods and services to impact their followers' life, fabricate behavior and motivate choices.

KEY WORDS: Digital influence makers; New Technologies; civil responsibility; Consumers' Law Code.

\section{RESPONSABILIDAD CIVIL DE LOS INFLUENCIADORES DIGITALES}

RESUMEN: La publicidad en Brasil está reglada en el ámbito estatal y en el ámbito privado, con la finalidad de inhibir la publicidad ilícita, que puede presentarse de forma abusiva y/o engañosa, garantizando, así, los derechos de los consumidores. Con el avance de la tecnología y de las facilidades que la Internet puede ofrecer, se vive, actualmente, en una sociedad de exposición, en que cada vez más los individuos comparten sus intereses y opiniones. Surge entonces la figura del influenciador digital, individuo formador de opinión digital, capaz de modificar comportamientos de sus seguidores. En el artículo se evalúa la responsabilidad civil de los influenciadores digitales en razón de indicación de productos y servicios, justificándose el estudio frente a las vulnerabilidades de los consumidores. El método lógico-deductivo fue la base metodológica del estudio, partiendo del entendimiento de la publicidad y su reglamentación en Brasil para alcanzar los influenciadores digitales y discutir su responsabilidad civil. Se concluye por la responsabilidad objetiva de los influenciadores, porque ellos están en ventaja cuando comparados a los consumidores y actúan efectivamente por intermedio de la indicación de productos y servicios, de modo a impactar la vida de sus seguidores, moldar comportamientos y motivar escojas de consumo.

PALABRAS CLAVE: Influenciadores digitales; Nuevas tecnologías; Responsabilidad civil; Código de Defensa del Consumidor. 


\section{INTRODUÇÃO}

A publicidade auxilia no desenvolvimento do mercado e da economia sendo utilizada para informar e, principalmente, para alterar o comportamento de compra dos consumidores. Diante da maior acessibilidade e disponibilidade da internet foram criadas novas formas de interação entre as pessoas, deflagrando mudanças comportamentais, sociais e econômicas. Tudo isto em um contexto em que novas tecnologias são desenvolvidas e incorporadas ao dia a dia das pessoas. Vive-se a quebra de paradigmas. Conceitos como velocidade, acessibilidade, mobilidade, distância e sociabilidade estão em constante modificação. $O$ foco é a mudança, a velocidade e a urgência com que a sociedade contemporânea, por meio da tecnologia, vive, consume e se relaciona.

A divulgação de todo tipo de dados (texto, imagem, som, vídeo) na internet e a rapidez com que as informações se propagam proporcionam às empresas uma nova possibilidade de difundir sua marca, ampliar os lucros e angariar mais clientes. O comércio eletrônico (e-commerce) já é realidade e o ato de "comprar" se transformou em "clicar".

Muitos são os fatores que influenciam o comportamento do consumidor, contudo, um elemento em específico tem chamado à atenção pelo grande poder de influência e convencimento exercido na sociedade de informação, qual sejam os influenciadores digitais.

$\mathrm{O}$ artigo trata da figura do influenciador digital e de seu poder de influência no comportamento de compra dos consumidores, sendo que os influenciadores diante do Código de Defesa do Consumidor podem ser equiparados a fornecedores e, portanto, questiona-se a responsabilidade civil desses influenciadores quando indicam produtos ou serviços por meio da internet. Num primeiro momento, podese apontar que um influenciador digital serve como um criador de conteúdo para gerar engajamento entre consumidores e marcas patrocinadoras.

Questiona-se, portanto: a responsabilização civil é objetiva ou subjetiva? Por que os influenciadores exercem tanta influência sobre seus seguidores? Existem mecanismos na legislação brasileira para responsabilizar os influenciadores digitais por eventuais danos causados? Diante disso, tais aspectos requerem estudo e atenção tanto por parte dos pesquisadores quanto por parte da sociedade contemporânea que é tecnológica e informacional. 
$\mathrm{O}$ artigo utiliza o método dedutivo para analisar os preceitos consumeristas, a fim de verificar a possibilidade de responsabilização dos influenciadores digitais frente ao Código de Defesa do Consumidor, tendo em vista o poder de persuasão que eles exercem sobre os seus seguidores aqui entendidos como consumidores.

\section{A PUBLICIDADE E SUA REGULAMENTAÇÃO NO BRASIL}

O desenvolvimento da atividade publicitária é um dos principais fenômenos que trouxe consequências para o surgimento e o desenvolvimento do mercado de consumo na sociedade da informação. ${ }^{04} \mathrm{E}$, apesar da Constituição Federal de 1988 não tratar diretamente sobre publicidade em seu texto, ela traz alguns artigos relacionados, tal qual o art. 50, IX, que determina: "É livre a expressão da atividade intelectual, artística, científica e de comunicação, independentemente de censura ou licença". ${ }^{55}$ Ademais, o capítulo $\mathrm{V}$ da Constituição dispõe sobre a comunicação social, que se correlaciona com o tema em análise.

Miragem ${ }^{06}$ entendequea publicidade estáfundamentadaconstitucionalmente na livre iniciativa, prevista no art. $1^{\circ}, \mathrm{IV}$, da CF, sendo que tal garantia deve estar harmonizada com a defesa dos interesses do consumidor, uma vez que a livre iniciativa é princípio informador da ordem econômica constitucional.

Ressalta-se que a publicidade é regulamentada por diversas leis conforme matérias e temas específicos, tais como Lei das Contravenções Penais (anúncio de processo, substância ou objeto destinado a provocar aborto, divulgação de loterias e imitação de moeda); decreto 3.665/2000 e lei n. 10.826/2003 (publicidade ilícita de armas de fogo); Código Civil (uso de nome, apelido e imagem das pessoas); lei n. 9.610/98 (direitos autorais); lei n. 4.680/65, decretos 57.690/66, 2.262/97 e 4.567/02 (exercício da profissão de publicitário); lei federal n 5.197/67 (utilização de animais da fauna silvestre em anúncios publicitários); lei 6.360/76 e resolução da Anvisa RDC 102/00 (publicidade de medicamentos); A lei 9.294/96 (restrições à propaganda de produtos fumígeros, bebidas alcoólicas, medicamentos, terapias e defensivos agrícolas); lei n. 5.768/71 e decreto n. 70.951/72 (promoções comerciais e sorteios, prêmios e brindes); lei n. 5.700/71 (Símbolos Nacionais); lei 8.979/95 (condições

\footnotetext{
${ }^{04}$ MIRAGEM, Bruno. Curso de direito do consumidor. 6. ed. São Paulo: Revista dos Tribunais, 2016.

${ }^{05}$ BRASIL. Constituição da República Federativa do Brasil de 1988. Brasília, DF: Poder Executivo. 1988.

${ }^{06}$ MIRAGEM, op. cit., p. 267.
} 
para varejo e vendas a prazo); lei n. 11.265/2006 (regulamenta a comercialização de alimentos para lactantes e crianças de primeira infância e também de produtos de puericultura correlatos) e a lei 9.279/96 (propriedade industrial).

No Código de Defesa do Consumidor o tema é abordado na seção III, sendo que, "até a edição do CDC, apenas existiam regras éticas sobre o exercício da publicidade, nenhuma das quais oferecia proteção ao consumidor propriamente" ${ }^{\circ 7}$. Deste modo destaca-se que o CDC estabelece princípios que devem ser observados com relação à publicidade, quais sejam: princípio da vinculação; princípio da identificação; e princípio da veracidade e não abusividade. ${ }^{08}$

$\mathrm{O}$ princípio da vinculação está previsto no art. $30^{\circ}$ do $\mathrm{CDC}^{09}$, o qual estabelece que a oferta publicitária vincula o fornecedor ao seu cumprimento nos termos do anúncio, sendo que em caso de inobservância o fornecedor fica sujeito aos termos do art. $35^{\circ}$ do CDC, que por sua vez estabelece as consequências da realização da oferta e seu descumprimento. Por meio desse princípio fica demonstrada a preocupação do direito com relação ao poder de influência que a publicidade exerce sobre os consumidores. Efing ${ }^{10}$ aponta que "Desta forma, a oferta ou a publicidade tem por fim a celebração de um negócio jurídico e por tal razão há a obrigação de cumprimento nos exatos termos do que fora proposto."

No que tange ao princípio da identificação, disposto no art. $36^{\circ}$ do CDC, Efing $^{11}$ destaca que

Este artigo proibiu a publicidade clandestina, encoberta por reportagens, programas televisivos ou informativos impressos que impedem a imediata visualização do produto ou serviço que está sendo veiculado, técnica conhecida por merchandising. Assim, restou vedada a publicidade implícita, que confunde o consumidor e dificulta a identificação do bem ofertado.

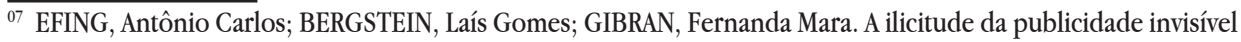
sob a perspectiva da ordem jurídica de proteção e defesa do consumidor. Revista de Direito do Consumidor, v. 21, n. 81, p. 91-116, São Paulo: Revista dos Tribunais, jan/mar. 2012, p. 96.

${ }^{08}$ AZEVEDO, Ney Queiroz. Sociedade da informação: os limites jurídicos da publicidade no Brasil à luz do Código de Defesa do Consumidor. Dissertação (Mestrado) - PUC/PR-PPGD, 2007, p. 59.

${ }^{09}$ BRASIL. Código de Defesa do Consumidor. Lei 8.078/1990. Brasília, DF: Poder Executivo, 1990.

${ }^{10}$ EFING, Antônio Carlos; BAUER, Fernanda Mara Gibran; ALEXANDRE, Camila Linderberg. Os Deveres anexos da boa-fé e a prática do neuromarketing nas relações de consumo: Análise jurídica embasada em direitos fundamentais. Revista Opinião Jurídica, Fortaleza, ano 11, n. 15, p. 38-53, jan./dez. 2013, p.42.

${ }^{11}$ EFING, Antônio Carlos. Fundamentos do direito das relações de consumo. Curitiba: Juruá, 2004, p. 190.
} 
Já com relação ao princípio da veracidade e não abusividade, que estão dispostos no art. $37^{\circ}$ do $\mathrm{CDC}$, cumpre ressaltar que tal princípio veda a publicidade ilícita que o CDC, divide em abusiva e enganosa. ${ }^{12}$

Nesse sentido é válido o entendimento de Marques e Miragem ${ }^{13}$, visto que para os autores "as regras presentes no CDC proibindo a veiculação de publicidade enganosa e publicidade abusiva, como verdadeiros atos ilícitos, parecem reforçar o regime ético da publicidade, estabelecido pelos arts. 30, 35, 36 e 38 do CDC".

A prática da publicidade ilícita fere o preceito constitucional do respeito à dignidade da pessoa humana, extrapolando os limites da legislação consumerista, infringindo os dois principais objetos protegidos pela regulação da publicidade, a saber: a vulnerabilidade do consumidor e os valores sociais. ${ }^{14}$

A publicidade abusiva, de que trata o art. $37^{\circ}$ do $\mathrm{CDC}$, parágrafo $2^{\circ}$, é a publicidade antiética, "que fere a vulnerabilidade do consumidor, que fere valores básicos sociais, que fere a própria sociedade como um todo" ${ }_{-}{ }^{15}$.

Já para a configuração da publicidade enganosa não há necessidade que o consumidor enganado obtenha o produto, isto é, não é imprescindível a ocorrência do erro de fato, bastando somente existir a probabilidade de o consumidor ser induzido a erro.

Para Miragem, ${ }^{16}$ a publicidade terá relevância jurídica para o direito em três situações, quais sejam: 1) quando a publicidade se apresenta como veículo de uma oferta de consumo, produzindo, com isso, efeito de vinculação do fornecedor, na condição de negócio jurídico unilateral; 2) quando a publicidade fere os preceitos do CDC, caracterizando-se como publicidade enganosa ou publicidade abusiva; e 3) quando a publicidade se apresenta como um contato social de consumo, que apesar de não possuir os requisitos de um negócio jurídico unilateral de oferta, veicula informação apta a produzir nos consumidores expectativas legítimas que em razão do princípio da boa-fé objetiva e da tutela da confiança, também impõe a eficácia vinculativa do fornecedor.

Quando se trata de publicidade, é importante ressaltar a criação em 1980 de uma organização não governamental que realiza o autocontrole do mercado

\footnotetext{
$\overline{{ }^{12} \text { AZEVEDO, op. cit., p. }} 61$.

13 MARQUES, Cláudia Lima; MIRAGEM, Bruno (org.). Direito do consumidor: fundamentos do direito do consumidor. São Paulo: Revista dos Tribunais, 2011, p. 1026.

${ }^{14}$ EFING; BERGSTEIN; GIBRAN, op. cit., p. 97.

${ }^{15}$ MARQUES, Claudia Lima. Contratos no Código de Defesa do Consumidor. São Paulo: RT, 1999, p. 482.

${ }^{16}$ MIRAGEM, op. cit., p. 266.
} 
publicitário, denominado Conselho Nacional de Autorregulamentação Publicitária (CONAR), o qual foi fundado com a finalidade de fazer cumprir o Código Brasileiro de Autorregulamentação Publicitária, código este aprovado durante o III Congresso de Propaganda realizado em São Paulo em 1978. ${ }^{17}$ O Conar recebe denúncias no que diz respeito à publicidade enganosa ou abusiva que cause constrangimento ao consumidor, sendo as denúncias julgadas pelo Conselho de Ética, o qual tem a responsabilidade de recomendar alterações ou suspender a veiculação do anúncio quando comprovada a procedência da denúncia.

Cláudia Lima Marques ${ }^{18}$ relata que a publicidade, na sociedade de massa, possui dupla função: informar e estimular o consumo de bens e serviços. Neste sentido Efing ${ }^{19}$ aponta que

A relevância da publicidade está ao se considerar uma sociedade de economia massificada, na qual diversos produtos e serviços são ofertados diariamente por meio de mensagens transmitidas pela televisão, do rádio, da Internet, de folders, de outdoors, e que expõem milhões de cidadãos no mundo à iminente necessidade de comprar e consumir.

A publicidade é considerada como uma informação direcionada ao público objetivando fomentar uma atividade econômica, tendo grande relevância em uma sociedade de hiperinformação, visto que o indivíduo é subjugado a uma grande quantidade de dados e informações o tempo todo e em qualquer lugar. Além disso, tal relevância é ressaltada, na medida em que a publicidade adota técnicas refinadas e profissionais para sua realização. ${ }^{20} 21$

Segundo Jacobina, ${ }^{22}$ a publicidade é "a arte de criar, no público, a necessidade de consumir". E, é por meio dessa arte que se analisa o comportamento do consumidor, que segundo Kotler ${ }^{23}$ é um conjunto de informações que auxiliam no conhecimento das culturas, valores, crenças e desejos, servindo de suporte para

\footnotetext{
${ }_{17}$ CONAR, Conselho Nacional de Autorregulamentação Publicitária. Disponível em: www.conar.org.br. Acesso em: 05 mar. 2018.

${ }^{18}$ MARQUES, op. cit., p. 482.

${ }^{19}$ EFING; BAUER; ALEXANDRE, op. cit., p.41.

${ }^{20}$ PASQUALOTO, Adalberto de Souza. Publicidade de tabaco e liberdade de expressão. Revista de Direito do Consumidor, São Paulo, v. 21, n. 82, p. 25, abr.jun. 2012, p.22.

${ }^{21}$ MIRAGEM, op. cit., p. 265.

${ }^{22}$ JACOBINA, Paulo Vasconcelos. Publicidade no direito do consumidor. Rio de Janeiro: Forense, 1996, p.15.

${ }^{23}$ KOTLER, Philip. Administração de marketing. 4. ed. São Paulo: Atlas, 1996, p. 27.
} 
entender como os consumidores tomam suas decisões, bem como identificar quem participa como influenciador nesse processo decisório.

$\mathrm{Na}$ visão de Blackwell, Miniard e Engel, ${ }^{24}$ diversos elementos podem influenciar o comportamento do consumidor, não somente os aspectos culturais, mas também elementos relacionados a outros fatores fundamentais como, por exemplo: personalidade de cada indivíduo, identidade étnica, fases da vida, valores obtidos ao longo da vida, rendimento, família, comportamento de compra, estímulos pessoais, experiências em compras anteriores e opiniões de influenciadores.

Assim, verifica-se que são vários os motivos que podem influenciar o comportamento do consumidor, sendo que cada vez mais a publicidade tem se utilizado de técnicas para fomentar o consumo e persuadir consumidores.

$\mathrm{Na}$ sequência, aborda-se a questão do impacto da publicidade sobre o consumidor e analisa-se um ator que atualmente vem exercendo grande influência na decisão de compra, qual seja: o influenciador digital; o qual a partir das facilidades ofertadas pela rede mundial de computadores vem se tornando um eficiente aliado na arte de criar nos indivíduos a necessidade de consumir.

\section{OS INFLUENCIADORES DIGITAIS E A RESPONSABILIDADE CIVIL SOB A ÓTICA DA SOCIEDADE DE EXPOSIÇÃO}

Atualmente a internet proporciona diferentes possibilidades daquelas que proporcionava em 1994 quando a rede foi aberta para fins comerciais: "Veiculase todo tipo de dado, ou seja, texto, imagem, vídeo, áudio; com velocidade, acessibilidade e mobilidade nunca antes possível." 25

De acordo com a Pesquisa Brasileira de Mídia - Hábitos de Consumo na Mídia pela População Brasileira, realizada pela Secretaria de Comunicação Social da Presidência da República, em 2016, 49\% dos brasileiros utilizavam a internet. Conforme dados do ano de 2015, o percentual de pessoas que utilizavam o meio

\footnotetext{
${ }^{24}$ BLACKWELL, Roger D.; MINIARD, Paul W.; ENGEL, James F. Comportamento do consumidor. 9. ed. São Paulo: Thomson Learning, 2005, p. 32.

${ }^{25}$ FREITAS, Cinthia Obladen de Almendra. A vulnerabilidade do consumidor e a exposição pública na internet. In: Aires José Rover, Fernando Galindo. (org.). III Encontro de Internacionalização do CONPEDI: Universidad Complutense de Madrid. Madrid: Ediciones Laborum, 2015, v. 9, p. 76-101. p.78.
} 
todos os dias, cresceu de $37 \%$ para 50\%, em $2016 .{ }^{26},{ }^{27}$ A pesquisa também revelou que os usuários da internet ficam conectados, em média, 04 horas em 44 minutos por dia durante a semana e $03 \mathrm{~h} 32 \mathrm{~min}$ nos finais de semana. ${ }^{28}$

O Brasil, segundo o Relatório TIC Domicílios 2016, possui 107,9 milhões de usuários de internet, sendo que $93 \%$ dos usuários utilizam o celular para acessar a $w e b .^{29} \mathrm{O}$ relatório também expõe que $89 \%$ dos usuários utilizam a internet para o envio de mensagens instantâneas e $78 \%$ para o uso de redes sociais. ${ }^{30}$

É neste contexto que a seguir são conceituados tanto a sociedade de exposição quanto os influenciadores digitais para, então, discutir sobre a responsabilidade civil destes atores.

\subsection{A SOCIEDADE DE EXPOSIÇÃO}

Na língua portuguesa, no Brasil, exposição é "substantivo feminino. Exibição pública; revelação". ${ }^{31}$.Nota-se que a exibição vem acompanhada do termo pública, ou seja, aos outros, à sociedade ou àqueles que integram uma rede de relacionamentos, sejam estes relacionamentos reais ou virtuais. Neste contexto, entende-se a formação da cultura de exposição tal qual descrita por Tim Wu, professor da Columbia University, explicando que "A cultura da exposição reflete a filosofia da web, na qual ser percebido é tudo". Anderson ${ }^{32}$ em seu livro "A Cauda Longa" (The Long Tail), mostra o que Tim Wu entende por cultura da exposição, a saber:

A cultura da exposição reflete a filosofia da Web, na qual ser percebido é tudo. Os autores da Web se ligam uns aos outros, citam com liberalidade e, às vezes, comentam ou anotam artigos inteiros. A transmissão por e-mail de links para artigos ou piadas favoritas integrou-se na cultura dos ambientes de trabalho americana, tanto quanto as conversas de bebedouro.

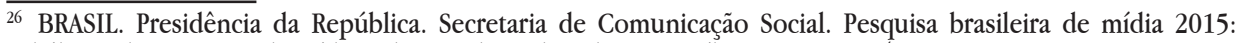
hábitos de consumo de mídia pela população brasileira. Brasília: Secom, 2014, p. 7.

${ }^{27}$ BRASIL. Presidência da República. Secretaria de Comunicação Social. Pesquisa brasileira de mídia 2016: hábitos de consumo de mídia pela população brasileira. Brasília: Secom, 2015, p. 48-49.

${ }^{28}$ Ibid., p. 48.

${ }^{29}$ COMITÊ GESTOR DA INTERNET NO BRASIL. Pesquisa sobre o uso das tecnologias da informação e da comunicação no Brasil: TIC Domicílios e Empresas 2016, Coordenação executiva e editorial/Alexandre F. Barbosa. São Paulo: Comitê Gestor da Internet no Brasil, 2017, p. 27.

${ }^{30}$ Ibid., p.47.

${ }^{31}$ BUENO, Silveira. Minidicionário da língua portuguesa. 2. ed. São Paulo: FTD, 2007, p. 341.

32 ANDERSON, Chris. A cauda longa. Tradução: Afonso Celso da Cunha Serra. 5. ed. Rio de Janeiro: Elsevier, 2006, p. 72.
} 
O grande pecado da cultura da exposição não é copiar, mas, em vez disso, deixar de citar de maneira adequada a autoria. No centro dessa cultura da exposição situa-se o todo poderoso software de pesquisa. Se for fácil encontrar o seu site no Google - não o acione em juízo, comemore.

O autor contextualiza a exposição no Direito de Autor, mas a preocupação é cabível a este artigo assim como é o conceito de exposição. A sabedoria popular dita que quem não está ou não pode ser encontrado por meio da Internet, não existe. Então, a informação gerou uma sociedade e a exposição também está gerando uma sociedade.

Isso mostra que o conteúdo pode ser compartilhado de forma livre, sendo o conteúdo inclusive sobre o próprio indivíduo que o produz e posta nas redes sociais. Este conteúdo autobiográfico tornou-se comum e vem sendo potencializado pelas redes sociais. Sibilia ${ }^{33}$ explica que "Todas essas tendências de exposição da intimidade que proliferam hoje em dia, portanto, vão ao encontro e prometem satisfazer uma vontade geral do público: a avidez de bisbilhotar e "consumir" vidas alheias".

De acordo com Freitas ${ }^{34}$, vive-se na sociedade da exposição, tendo em vista que "os indivíduos, cada vez mais compartilham interesses ou preocupações mútuas a partir de um objeto ou objetivo comum". Conceituando a sociedade de exposição como o "conjunto de pessoas que se utilizam das redes sociais para manter e ampliar os modos de comunicar e relacionar". O excesso de informação está diretamente atrelado ao excesso de exposição, exposição esta sem limites de cada indivíduo de maneira a refletir seus gostos, modo de vida, interesses, amigos, pensamentos e atitudes. A sociedade de exposição tem em seus indivíduos o objeto de interesse, sendo que tais indivíduos possuem por objetivo a exposição. Expor-se é a palavra de ordem. Deste modo, a estrutura comportamental das redes sociais é suportada pela arquitetura de visibilidade, permitindo que a exposição seja concretizada e que as pessoas se mostram a todos e, também, possam ser observadas.

\footnotetext{
33 SIBILIA, Paula. Os diários íntimos na internet e a crise da interioridade psicológica. Antroposmoderno, 2003, p. 5. Disponível em: http://antroposmoderno.com/antro-version-imprimir.php?id_articulo=1143. Acesso em: 05 mar. 2018.

${ }^{34}$ FREITAS, op. cit., p.81.
} 


\subsection{QUEM SÃO OS INFLUENCIADORES DIGITAIS?}

E foi dessa sociedade de exposição que surgiram os denominados influenciadores digitais. Essas celebridades do mundo digital são pessoas que se destacam na internet, seja por meio de blogs, redes sociais ou de plataformas de distribuição digital de vídeos (exemplo: YouTube), e que possuem know-bow na arte de angariar seguidores.

Os influenciadores digitais são grandes formadores de opinião, sendo capazes de modificar comportamentos e mentalidade de seus seguidores, visto que em razão da exposição de seus estilos de vida, experiências, gostos, preferências e, principalmente, da interação social acabam conquistando a confiança dos usuários ora consumidores (conhecidos como seguidores).

Diante dessa nova forma de interação social, mais especificamente entre os usuários de internet, as empresas passaram a investir na contratação dos influenciadores digitais para criar conteúdo em favor de suas marcas, gerando endosso e, assim, influenciando outros usuários. A denominada "Geração Y"35 se inspira nessas personalidades digitais como referência de comportamento, transferindo-se, com isso, a confiança depositada nesses influenciadores para as marcas. Este efeito cascata é quase que instantâneo assim que uma foto, resenha ou vídeo é postado indicando um produto ou serviço.

Uma pesquisa realizada pela consultoria Forrester ${ }^{36}$, discutida na Conferência Americana de Marketing Affilliate Summit de 2017, revela onde as marcas mais estão investindo para angariar clientes on-line, sendo que os influenciadores digitais aparecem em primeiro lugar com $22 \%{ }^{37}$

A respeito dos influenciadores digitais, Karhawi ${ }^{38}$ destaca:

\footnotetext{
${ }_{35}$ A geração Y é representada, de acordo com Tapscott (2010), pelos nascidos entre 1977 e 1997. Várias outras denominações também são utilizadas para identificar essa geração, tais como: Geração Digital, Millenials, Geração da Internet e Nativos Digitais. TAPSCOTT, Don. A hora da geração digital. Rio de Janeiro: Agir, 2010.

${ }^{36}$ FORRESTER. Networks help drive affilliate marketing into the mainstream - advertisers and publishers envolve as the industry shifts. 2016. Disponível em: https:/www.practicalecommerce.com/wp-content/ uploads/2016/03/Networks_Help_Drive_Affiliate_Marketing_Into_The_Mainstream.pdf. Acesso em: 05 mar. 2018.

${ }^{37}$ LOMADEE. O papel dos influenciadores para conquistar a confiança do consumidor. 2017. Disponível em: http://www.mktdeafiliados.com.br/post/affilliate-summit-2017-o-papel-dos-influenciadores-para-conquistar-aconfianca-do-consumidor.htm. Acesso em: 05 mar. 2018.

${ }^{38}$ KARHAWI, Issaaf. Influenciadores digitais: o eu como mercadoria. In: SAAD, Elizabeth; SILVEIRA, Stefanie C. (org.). Tendências em comunicação digital. São Paulo: ECA/USP, p. 39-58, 2016, p. 46-47. Disponível em: http://www.livrosabertos.sibi.usp.br/portaldelivrosUSP/catalog/download $/ 87 / 75 / 365-1$ ?inline $=1$. Acesso em: 05 mar. 2018.
} 
[...] os influenciadores digitais estão no Facebook, no Instagram, no Snapchat, em espaços ocupados por "pessoas comuns" com quem dialogam em igualdade. É por esse motivo, também, que revistas e sites de veículos tradicionais de mídia não têm a mesma reputação que os influenciadores digitais. A proximidade desses sujeitos de seus públicos, de sua rede, a partir da escrita íntima, do uso da primeira pessoa (no caso dos blogs, Instagram, Twitter) e da pessoalidade cria uma aproximação entre o criador de conteúdo e seus públicos. É nessa sustentação que se ergue o capital simbólico dos blogueiros e, muito fortemente, das blogueiras de moda que são encaradas como melhores amigas de suas leitoras.

De acordo com O'Neil-Hart e Blumenstein ${ }^{39}$, uma pesquisa realizada pela Google, revelou que 4 em cada dez usuários do YouTube confiam mais no seu youtuber favorito do que nos seus amigos, e que seis em cada dez optam por seguir uma indicação de produto/serviço realizada por seu youtuber favorito do que por outras celebridades.

Em uma pesquisa apresentada no Congresso Internacional de Administração, em setembro de 2017, constatou-se que em um universo de 414 internautas, 91,8\% seguem ao menos um influenciador digital em suas redes sociais, sendo que deste percentual, 78,5\% já tiveram contato com o ponto de venda de um produto indicado pelo influenciador digital. ${ }^{40} \mathrm{~A}$ pesquisa apresenta também que $74,9 \%$ aceitam, às vezes, as recomendações feitas pelos influenciadores e 48,6\% já adquiram algum produto que fora indicado por influenciadores digitais. ${ }^{41}$

De acordo com Guimarães: "Com o avançar dos anos os estudos sobre o comportamento do consumidor se foram aprimorando, a ponto de se poder prever qual sua reação a partir de certa motivação ou estímulo". "22 Assim, o autor assevera ainda que

\footnotetext{
39 O'NEIL-HART, Celie; BLUMENSTEIN, Howard. Why youtube stars are more influential than traditional celebrities. 2016. Disponível em: https://www.thinkwithgoogle.com/consumer-insights/youtube-starsinfluence/. Acesso em: 05 mar. 2018.

${ }^{40}$ BASTOS, Maria Augusta et al. $O$ impacto da utilização das redes sociais pelos digital influencers como ferramenta de marketing das empresas varejistas. In: CONGRESSO INTERNACIONAL DE ADMINISTRAÇÃO. Setembro, Ponta Grossa/PR, 2017, p.1-11. Disponível em: http://www.admpg.com.br/2017/down.php?id=3147\&q=1. Acesso em: 05 mar. 2018. p. 8.

${ }^{41}$ BASTOS et al., op. cit., p. 9-10.

${ }^{42}$ GUIMARÃES, Paulo Jorge Scartezzini. A Publicidade ilícita e a responsabilidade civil das celebridades que dela participam. São Paulo: RT, 2001. p. 98.
} 
[...] é nesse desbravamento e exploração da mente humana que os publicitários se apoiam e buscam as inspirações para seus anúncios. Criam eles necessidades e após manipulam os consumidores em direção ao produto ou serviço que irá supri-las. Criam efetivamente desejos supérfluos, que, logo em seguida, graças às suas técnicas, são transformadas em produtos imprescindíveis. Assim, estão corretos aqueles que, primeiramente, surge o produto ou serviço; depois é que se inventa a necessidade.

A massificação da produção, do consumo e do crédito gerou essa nova arquitetura social, em que para se alcançar elevados índices de vendas e lucro, é necessária uma grande difusão da publicidade e das estratégias mercadológicas, tornando, assim, o consumidor vulnerável às ações dos produtores e fornecedores de bens e serviços. ${ }^{43}$

E é nesse cenário que os influenciadores digitais se tornam grandes aliados na divulgação e indicação de produtos e serviços, visto que eles conseguem impactar a vida dos seus seguidores, moldar comportamentos e motivar escolhas de consumo.

Dessa feita, é fácil notar que a tecnologia tem impulsionado a disseminação da publicidade, contribuindo com o surgimento de novos arranjos no que tange às relações de consumo e à responsabilidade por eventuais danos aos consumidores. Surge com isso a possibilidade de responsabilização dos influenciadores digitais quando da indicação de produtos ou serviços.

\subsection{A RESPONSABILIDADE CIVIL}

Primeiramente deve-se refletir tal qual Guimarães ${ }^{44}$ questionando a responsabilidade civil das celebridades que participam e realizam publicidade de produtos e serviços, a ponto de serem caracterizados danos em decorrência de publicidade ilícita. Para o autor, em um primeiro momento as celebridades podem não ter o dever de indenizar, visto não terem relação direta com o bem anunciado, veiculando nas publicidades texto criado por outrem, a exemplo dos publicitários. Por outro lado, o autor entende que toda atividade profissional gera responsabilidade civil por eventuais danos, sendo obrigado a indenizar àqueles que sofrerem os danos. O autor faz lembrar que as celebridades recebem valores significativos para atuar em comerciais e campanhas publicitárias.

\footnotetext{
$\overline{43}$ EFING; BERGSTEIN ; GIBRAN, op. cit., p. 97.

${ }^{44}$ GUIMARÃES, op. cit., p. 19.
} 
Nesse sentido também é o entendimento de Campos ${ }^{45}$.

Esse tipo de publicidade desencadeia um comportamento no consumidor, em nível consciente e inconsciente, gerando uma resposta imediata devido ao conceito preexistente que se tem daquela pessoa ou grupo que está testemunhando a favor do produto, agregando-lhe valores como admiração, sucesso, riqueza, beleza, juventude, alegria, internacionalidade, tradição, notoriedade, etc.

Guimarães ${ }^{46}$ apresenta ainda o entendimento do Tribunal de Alçada de Minas Gerais que decidiu

[...] a teoria da confiança atribui responsabilidade àquele que, por seu comportamento na sociedade, gera no outro contratante justificada expectativa no adimplemento de determinadas obrigações. A publicidade integrará o contrato, de acordo com o art. 30 do CDC.

Para Efing, ${ }^{47}$ ao ser verificada a violação aos direitos básicos do consumidor, por meio de publicidade enganosa e abusiva, a legislação brasileira autoriza o uso de medidas sancionatórias, as quais possuem duplo objetivo: a) punir o infrator e b) reprimir a utilização do mesmo tipo metodológico por outros agentes publicitários; tendo em vista a observância do princípio da boa-fé, que representa uma regra de conduta para ambas as partes da relação consumerista, as quais devem agir pautadas pela honestidade e lealdade.

No entendimento de Larenz ${ }^{48}$, "o princípio da boa-fé significa que cada um deve guardar fidelidade com a palavra dada e não frustrar a confiança ou abusar dela, já que esta forma a base indispensável de todas as relações humanas.”.

Tendo em vista a recorrência da participação de pessoas famosas em publicidade, o Código de Ética Publicitário ${ }^{49}$ dispõe que

\footnotetext{
${ }^{45}$ CAMPOS, Maria Luiza de Sabóia. Publicidade: responsabilidade civil perante o consumidor. São Paulo: Cultura Paulista, 1996. p. 222.

${ }^{46}$ GUIMARÃES, op. cit., p. 167.

${ }^{47}$ EFING; BERGSTEIN; GIBRAN, op. cit., p. 97.

${ }^{48}$ LARENZ, Karl. Derecho de obligaciones, t. I. Trad. Jaime Santos Brinz. Madrid: Revista de Derecho Privado. 1958. p. 142.

${ }^{49}$ CONAR, op. cit.
} 
2.1. O anúncio que abrigar o depoimento de pessoa famosa deverá, mais do que qualquer outro, observar rigorosamente as recomendações do Código.

2.2. O anúncio apoiado em testemunhal de pessoa famosa não deverá ser estruturado de forma a inibir o senso crítico do consumidor em relação ao produto.

2.3. Não será aceito o anúncio que atribuir o sucesso ou fama da testemunha ao uso do produto, a menos que isso possa ser comprovado.

2.4. O Anunciante que recorrer ao testemunhal de pessoa famosa deverá, sob pena de ver-se privado da presunção de boa-fé, ter presente a sua responsabilidade para com o público.

Em que pese a elaboração do CDC não ser concomitante ao surgimento da figura do influenciador digital e sua constante utilização nas publicidades, deve-se atribuir aos influenciadores responsabilidade de reparação frente aos consumidores, em razão da indicação de produtos e serviços. Eis que tais pessoas possuem grande poder de influência, além de contarem com a confiança de seus seguidores.

No momento em que um influenciador digital indica um produto ou serviço, a sua confiabilidade agrega poder persuasivo no comportamento do consumidor, gerando segurança sobre a qualidade daquele produto ou serviço que está sendo indicado. Os influenciadores assumem, portanto, uma posição de garantidores em face dos produtos e serviços indicados. Caso as qualidades atribuídas aos produtos e serviços não sejam condizentes com a realidade, o fator de persuasão os influenciadores aparece de forma negativa e prejudicial ao consumidor, confrontando, assim, os princípios da boa-fé e da confiança.

De acordo com Guimarães, ${ }^{50}$ devem ser aplicadas às celebridades todas as diretrizes do $\mathrm{CDC}$, inclusive no que concerne a responsabilidade em caso de violação aos direitos dos consumidores, tendo em vista que as celebridades são partes integrantes da cadeia de consumo, figurando ao lado de todos os outros agentes.

Como é sabido, o CDC, considerando a vulnerabilidade do consumidor, adotou a responsabilidade objetiva do causador do dano, com base na teoria do risco. Além da responsabilidade objetiva como regra, o CDC estabelece a solidariedade entre todos os envolvidos na veiculação da oferta, sendo que o parágrafo único do art.

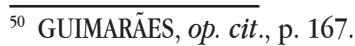


$7^{\circ}$ prevê que "tendo mais de um autor a ofensa, todos responderão solidariamente pela reparação dos danos previstos nas normas de consumo" ${ }^{\text {. }}$.

O princípio da solidariedade, que também é contemplado pela Constituição Federal, nos arts. $1^{\circ}$ (inciso IV) e $170^{\circ}$, "promove a repartição de riscos sociais em vista da melhor satisfação dos consumidores vítimas de eventos no mercado de consumo $[\ldots]^{\prime \prime 2}$.

Marques $^{53}$ preleciona em sua obra que o Superior Tribunal de Justiça vem entendendo que a responsabilidade no que tange à publicidade se estende àqueles que a veiculam e àqueles que dela se aproveitam.

Tratando-se de risco profissional (responsabilidade própria do profissional), tratando-se de atuação à qual a lei impõe deveres especiais (através de normas de ordem pública) não transferíveis aos consumidores, nem mesmo através de previsão contratual (ex vi arts. $1^{\circ}, 51$, I, e 25 do CDC), terá o fornecedor de suportar a sua falha, responder pela informação mal transmitida, pelo inadimplemento contratual ou pelo ato ilícito eventualmente resultante da publicidade falha. E notese que a jurisprudência do STJ tem considerado solidária a responsabilidade daquele que veicula e daquele que se aproveita da publicidade (art. $30 \mathrm{c} / \mathrm{c} 35$ e art. 37 do CDC).

De acordo com Miragem, ${ }^{54}$ este é o caso que a doutrina contemporânea vem denominando de 'fornecedores por equiparação', ampliando com isso a responsabilidade pelos termos da oferta. Para Marques et al., ${ }^{55}$ o fornecedor por equiparação é "aquele terceiro na relação de consumo, um terceiro apenas intermediário ou ajudante da relação de consumo principal, mas que atua frente a um consumidor ou a um grupo de consumidores como se fornecedor fosse.".

Nesse compasso, os influenciadores digitais, assim como outras celebridades, devem ser responsabilizados por eventuais danos causados aos consumidores, haja vista que, como dito anteriormente, os seguidores passam a adquirir produtos e serviços com base na confiança e na boa-fé, que, aliás, são princípios norteadores do direito do consumidor.

\footnotetext{
$\overline{51}$ BRASIL. Código de Defesa do Consumidor. Lei n. 8.078/1990. Brasília, DF: Senado, 1990.

52 BRASIL. Constituição da República Federativa do Brasil. Brasília, DF: Senado, 1988.

${ }^{53}$ MARQUES, op. cit., p. 629-630.

${ }^{54}$ MIRAGEM, op. cit., p. 264.

55 MARQUES, Cláudia Lima, BENJAMIM, Antônio H. V., BESSA, Leonardo Roscoe. Manual de direito do consumidor. São Paulo: Revista dos Tribunais, 2007. p. 83.
} 
Assim, ensina Guimarães ${ }^{56}$ :

A celebridade, para responder pelos danos causados em decorrência de sua informação, deve ter um benefício, seja ele qual for. Em regra, esse benefício está no cachê previamente recebido ou no ganho na participação das vendas, porém haverá, ainda, responsabilidade da personalidade mesmo que a remuneração seja destinada a um órgão que diretamente esteja a ela ligado, como, por exemplo, um antigo comercial da Honda, feito pela filha de Juscelino Kubitschek, cuja remuneração foi destinada à Fundação JK, ou quando a personalidade doa o cachê para alguma instituição de caridade.

Após a configuração da responsabilidade dos influenciadores digitais, se faz necessário estabelecer se tal responsabilidade é objetiva ou subjetiva. Muito se discute a respeito da responsabilidade das celebridades, e aqui se incluem os influenciadores digitais, sendo que parcela afirma se tratar de responsabilidade subjetiva, visto que contribuem apenas com sua imagem: "pouco razoável responsabilizar a celebridade objetivamente quando apenas anuncia determinado produto sobre o qual não possui conhecimento técnico para avaliá-lo" ${ }^{57}$, e se "caso demandado, deverá, portanto, provar que não agiu com culpa ao participar da publicidade viciada"58.

Por outro lado, há os que entendem que se trata de responsabilidade objetiva, tendo em vista a teoria do risco adotado pelo CDC atrelado ao princípio da solidariedade e à obtenção de vantagem econômica com as atividades promovidas. ${ }^{59}$ Nesse sentido é o entendimento de Tartuce e Neves ${ }^{60}$ que

[...] cumpre trazer a lume questão de debate relativa à responsabilidade civil das celebridades, artistas, atletas e outras pessoas com notoriedade que atrelam o seu nome a de produtos e serviços no meio de oferta ou publicidade,

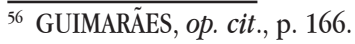

57 SPERANZA, Henrique de Campos Gurgel. Publicidade enganosa e abusiva. Disponível em: http://www. ambito-juridico.com.br/site/?n_link=revista_artigos_leitura\&artigo_id=11909. Acesso em: 05 mar. 2018.

${ }^{58}$ OLIVEIRA, Stéphane Assis Pinto. Responsabilidade das celebridades em campanhas publicitárias de crédito consignado destinados a idosos. Revista Jurídica Cesumar - Mestrado, v. 10, n. 2, p. 495-504, jul./dez. 2010. p. 502 .

59 MACEDO JUNIOR, Sergio Gonçalves. Responsabilidade civil das celebridades na publicidade ilícita. In Direito, Globalização e Responsabilidade nas relações de consumo. I Encontro Internacional do Conpedi Montevidéu/Uruguai, 2016, p. 191-211.

${ }^{60}$ TARTUCE, Flávio; NEVES, Daniel Amorim Assumpção. Manual de direito do consumidor. 6. ed. rev., atual. e ampl. Rio de Janeiro: Forense; São Paulo: MÉTODO, 2017. p. 222.
} 
os chamados garotos propaganda, ou melhor, garotos publicidade.

A tese de responsabilização de tais pessoas é defendida pelo magistrado e professor Paulo Jorge Scartezzini Guimarães, contando com o apoio de outros doutrinadores, caso de Herman Benjamin e Fábio Henrique Podestá, especialmente quando tais celebridades recebem porcentagem pelas vendas realizadas. A premissa teórica igualmente conta com o apoio deste autor, pois a tese representa outra importante aplicação da teoria da aparência, valorizando-se mais uma vez a boa-fé objetiva nas relações de consumo, em prol dos consumidores. Não se olvide que, muitas vezes, os vulneráveis adquirem produtos e serviços diante da confiança depositada em tais artistas ou celebridades.

Miragem $^{61}$ traz uma lógica a respeito da responsabilização objetiva das celebridades no que tange aos efeitos patrimoniais decorrentes da realização da publicidade enganosa e da atuação de outros sujeitos na divulgação de anúncios publicitários (incluindo as agências de publicidade), de modo a organizar o pensamento em duas linhas, a saber: a) pela responsabilidade objetiva solidária dos demais sujeitos, o autor aponta que estes também são remunerados pelos ganhos da publicidade, razão pela qual devem respondem de modo objetivo solidário por eventuais danos aos consumidores, fazendo menção aos arts. $7^{\circ}$ e $38^{\circ}$ do $\operatorname{CDC}$ sobre a responsabilidade dos demais integrantes da cadeia de consumo e b) pela responsabilidade das celebridades que atuam em anúncios publicitários e emprestam sua credibilidade perante o público para promover produtos ou serviços, razão pela qual o autor aponta que as celebridades deveriam arcar com os riscos decorrentes desta atuação.

Por fim, Guimarães ${ }^{62}$, ao tratar da responsabilidade das celebridades no que tange à participação em publicidade ilícita entende que aqueles não podem ser comparados a profissionais liberais, conforme se verifica:

As celebridades não poderiam ser conceituadas como profissionais liberais, pois, além de, em regra, não serem contratadas para participar das publicidades por causa de suas qualidades intelectuais ou técnicas - mas sim por 
qualidades externas, como a beleza, o prestígio, a fama- não são contratadas pelos consumidores intuitu personae, isto é, para cuja escolha foram relevantes os elementos confiança e competência, mas sim impostas a esses pelos anunciantes.

Tartuce e Neves ${ }^{63}$ lembram que não se pode olvidar que a confiança e a boa-fé objetiva são princípios de ordem pública e a quebra de tais preceitos gera a responsabilidade sem culpa (Enunciado $n^{\circ} 363$ do CJF/STJ), o que, em regra, está presente em relação à oferta ou à publicidade.

Nesse contexto, em razão do poder de persuasão que os influenciadores digitais exercem sobre seus seguidores, usuários de internet por meio da sociedade de exposição, bem como a confiança dispensada a eles e a vantagem econômica que recebem, entende-se que a responsabilidade dos influenciadores digitais é objetiva, tendo em vista os princípios da boa-fé e solidariedade, sem esquecer a necessária opção do legislador em proteger a parte mais vulnerável da relação consumerista que é o consumidor.

\section{CONSIDERAÇÕES FINAIS}

Vive-se a sociedade tecnológica, digital, da informação e da exposição. Ser visto por meio da internet é o que comanda as atitudes e escolhas dos consumidores, tendo a "Geração Y" deflagrado um "boom" de influenciadores digitais. Os influenciadores digitais sabem se aproximar e falar a linguagem da "Geração Y", utilizando as TICs como principal meio de acesso aos seus seguidores e fazendo uso de redes sociais e canais de vídeo, por exemplo, o YouTube.

Neste contexto, o artigo analisou a responsabilidade civil dos influenciadores digitais tendo por base o $\mathrm{CDC}$, de modo a configurar violação aos direitos dos consumidores equiparando os influenciadores digitais aos fornecedores, em razão da indicação de produtos ou serviços por meio da internet.

Constatou-se que os influenciadores digitais exercem papel fundamental na cadeia de relação de consumo, uma vez que são capazes de mudar comportamentos e opiniões, por exercerem poder suficiente tanto na "Geração Y" quanto em futuras gerações, de modo a indicar marcas ou apontar determinado produto ou serviço,

$\overline{63}$ TARTUCE; NEVES, op. cit., p. 218. 
norteando grande parte das decisões de compra de seus seguidores. O artigo discute os princípios da boa-fé objetiva e da confiança. E é justamente a violação de tais princípios que encontra no $\mathrm{CDC}$ a tutela necessária para proteger o usuárioconsumidor frente aos influenciadores digitais. Tem-se, portanto, responsabilidade objetiva, visto que os influenciadores estão em vantagem quando comparados aos consumidores, os quais são a parte vulnerável da relação consumerista.

Assim, ao se asseverar pela responsabilidade objetiva dos influenciadores digitais, tem-se por base que eles: a) fazem parte da cadeia de consumo, respondendo solidariamente pelos danos causados, b) recebem vantagem econômica e c) se relacionam diretamente com seus seguidores que são consumidores.

Há que se ter em mente que o consumidor, além de ser parte vulnerável da relação de consumo, está imerso na sociedade de exposição, sendo que os influenciadores digitais atuam efetivamente por meio da indicação de produtos e serviços, de modo a impactar a vida dos seus seguidores, moldar comportamentos e motivar escolhas de consumo.

\section{REFERÊNCIAS}

ANDERSON, Chris. A cauda longa. Tradução: Afonso Celso da Cunha Serra. 5. ed. Rio de Janeiro: Elsevier, 2006.

AZEVEDO, Ney Queiroz. Sociedade da informação: os limites jurídicos da publicidade no Brasil à luz do Código de Defesa do Consumidor. Dissertação Mestrado. PUC/PR-PPGD. Orientador: Antônio Carlos Efing, 2007.

BASTOS, Maria Augusta; BRITO, Bianca Camila; COUTINHO, Liliam Maisa; PINHO, Maria Carolina; BENTO, Kaique Dias. O impacto da utilização das redes sociais pelos digital influencers como ferramenta de marketing das empresas varejistas. In: CONGRESSO INTERNACIONAL DE ADMINISTRAÇÃO, Setembro, Ponta Grossa/ PR, 2017. Anais eletrônicos [...]. p.1-11. Disponível em: http://www.admpg.com. br/2017/down.php?id=3147\&q=1. Acesso em: 05 mar. 2018.

BLACKWELL, Roger D.; MINIARD, Paul W.; ENGEL, James F. Comportamento do consumidor. 9. ed. São Paulo: Thomson Learning, 2005.

BRASIL. Constituição da República Federativa do Brasil de 1988. Brasília, DF: Poder Executivo. 1988. 
BRASIL. Código de Defesa do Consumidor. Lei 8.078/1990. Brasília, DF: Poder Executivo. 1990.

BRASIL. Presidência da República. Secretaria de Comunicação Social. Pesquisa brasileira de mídia 2015: hábitos de consumo de mídia pela população brasileira. Brasília: Secom, 2014.

BRASIL. Presidência da República. Secretaria de Comunicação Social. Pesquisa brasileira de mídia 2016: hábitos de consumo de mídia pela população brasileira. Brasília: Secom, 2015.

BUENO, Silveira. Minidicionário da língua portuguesa. 2. ed. São Paulo: FTD, 2007.

CAMPOS, Maria Luiza de Sabóia. Publicidade: responsabilidade civil perante o consumidor. São Paulo: Cultura Paulista, 1996.

COMITÊ GESTOR DA INTERNET NO BRASIL. Pesquisa sobre o uso das tecnologias da informação e da comunicação no Brasil: TIC Domicílios e Empresas 2016, Coordenação executiva e editorial/Alexandre F. Barbosa. São Paulo: Comitê Gestor da Internet no Brasil, 2017.

CONAR, Conselho Nacional de Autorregulamentação Publicitária. Disponível em: www.conar.org.br. Acesso em: 05 mar. 2018.

EFING, Antônio Carlos. Fundamentos do direito das relações de consumo. Curitiba: Juruá, 2004.

EFING, Antônio Carlos; BAUER, Fernanda Mara Gibran; ALEXANDRE, Camila Linderberg. Os Deveres anexos da Boa-fé e a prática do neuromarketing nas relações de consumo: Análise jurídica embasada em direitos fundamentais. Rev.Opin. Jur., Fortaleza, ano 11, n. 15, p. 38-53, jan./dez. 2013.

EFING, Antônio Carlos; BERGSTEIN, Laís Gomes; GIBRAN, Fernanda Mara. A ilicitude da publicidade invisível sob a perspectiva da ordem jurídica de proteção e defesa do consumidor. Revista de Direito do Consumidor, v. 21, n. 81, p. 91-116, jan/mar. 2012.

FORRESTER. Networks help drive affilliate marketing into the mainstream: 
Advertisers and publishers envolve as the industry shifts. 2016. Disponível em: https://www.practicalecommerce.com/wp-content/uploads/2016/03/Networks Help_Drive_Affiliate_Marketing_Into_The_Mainstream.pdf. Acesso em: 05 mar. 2018.

FREITAS, Cinthia Obladen de Almendra. A Vulnerabilidade do consumidor e a exposição pública na internet. In: ROVER, Aires José; GALINDO, Fernando (org.). Encontro de Internacionalização do Conpedi, 3., 2015. Universidad Complutense de Madrid. Madrid: Ediciones Laborum, 2015, v. 9, p. 76-101.

GUIMARÃES, Paulo Jorge Scartezzini. A Publicidade ilícita e a responsabilidade civil das celebridades que dela participam. São Paulo: RT, 2001.

JACOBINA, Paulo Vasconcelos. Publicidade no Direito do Consumidor. Rio de Janeiro: Forense, 1996.

KARHAWI, Issaaf. Influenciadores digitais: o eu como mercadoria. In: SAAD, Elizabeth; SILVEIRA, Stefanie C. (org.). Tendências em comunicação digital. São Paulo: ECA/USP, 2016. p. 39-58. Disponível em: http://www.livrosabertos.sibi.usp. br/portaldelivrosUSP/catalog/download/87/75/365-1?inline=1. Acesso em: 05 mar. 2018.

KOTLER, Philip. Administração de marketing. 4. ed. São Paulo: Atlas, 1996.

LARENZ, Karl. Derecho de obligaciones, t. I. Trad. Jaime Santos Brinz. Madrid: Editora Revista de Derecho Privado. 1958.

LOMADEE. O papel dos influenciadores para conquistar a confiança do consumidor. 2017. Disponível em: http://www.mktdeafiliados.com.br/post/ affilliate-summit-2017-o-papel-dos-influenciadores-para-conquistar-a-confianca-doconsumidor.htm. Acesso em: 05 mar. 2018.

MACEDO JUNIOR, Sergio Gonçalves. Responsabilidade civil das celebridades na publicidade ilícita. In: ENCONTRO INTERNACIONAL DO CONPEDI, 1., Direito, Globalização e Responsabilidade nas relações de consumo. Montevidéu, URU: 2016, p. 191-211.

MARQUES, Claudia Lima. Contratos no Código de Defesa do Consumidor. São Paulo: RT, 1999. 
MARQUES, Cláudia Lima, BENJAMIM, Antônio H. V., BESSA, Leonardo Roscoe. Manual de direito do consumidor. São Paulo: Revista dos Tribunais, 2007.

MARQUES Cláudia Lima; MIRAGEM, Bruno (org.). Direito do consumidor: fundamentos do direito do consumidor. São Paulo: Revista dos Tribunais, 2011.

MIRAGEM, Bruno. Curso de direito do consumidor. 6. ed. São Paulo: Revista dos Tribunais, 2016.

OLIVEIRA, Stéphane Assis Pinto. Responsabilidade das celebridades em campanhas publicitárias de crédito consignado destinados a idosos. Revista Jurídica Cesumar - Mestrado, v. 10, n. 2, p. 495-504, jul./dez. 2010.

O'NEIL-HART, Celie; BLUMENSTEIN, Howard. Why youtube stars are more influential than traditional celebrities. 2016. Disponível em: https://www. thinkwithgoogle.com/consumer-insights/youtube-stars-influence/. Acesso em: 05 mar. 2018.

PASQUALOTO, Adalberto de Souza. Publicidade de tabaco e liberdade de expressão. Revista de Direito do Consumidor, São Paulo, v. 21, n. 82, p. 25, abr./ jun. 2012.

SIBILIA, Paula. Os Diários Íntimos na Internet e a Crise da Interioridade Psicológica. Antroposmoderno, 2003. Disponível em: http://antroposmoderno. com/antro-version-imprimir.php?id_articulo=1143. Acesso em: 05 mar. 2018.

SPERANZA, Henrique de Campos Gurgel. Publicidade enganosa e abusiva. Disponível em: http://www.ambito-juridico.com.br/site/?n_link=revista_artigos_ leitura\&artigo_id=11909. Acesso em: 05 mar. 2018.

TARTUCE, Flávio; NEVES, Daniel Amorim Assumpção. Manual de Direito do Consumidor. 6. ed. rev., atual. e ampl. Rio de Janeiro: Forense; São Paulo: MÉTODO, 2017.

TAPSCOTT, Don. A hora da geração digital. Rio de Janeiro: Agir, 2010. 